\title{
Landslide Occurrence Prediction Using Trainable Cascade Forward Network and Multilayer Perceptron
}

\author{
Mohammad Subhi Al-batah, ${ }^{1}$ Mutasem Sh. Alkhasawneh, ${ }^{2}$ Lea Tien Tay, ${ }^{2}$ \\ Umi Kalthum Ngah, ${ }^{2}$ Habibah Hj Lateh, ${ }^{3}$ and Nor Ashidi Mat Isa ${ }^{2}$ \\ ${ }^{1}$ Department of Software Engineering, Faculty of Science and Information Technology, Jadara University, Irbid 2001, Jordan \\ ${ }^{2}$ School of Electrical \& Electronic Engineering, Universiti Sains Malaysia, Engineering Campus, 14300 Nibong Tebal, Penang, Malaysia \\ ${ }^{3}$ School of Distance Education, Universiti Sains Malaysia, 11600 Penang, Malaysia \\ Correspondence should be addressed to Mutasem Sh. Alkhasawneh; m_sh_kal@yahoo.com
}

Received 28 September 2014; Revised 18 December 2014; Accepted 25 December 2014

Academic Editor: Yudong Zhang

Copyright (C) 2015 Mohammad Subhi Al-batah et al. This is an open access article distributed under the Creative Commons Attribution License, which permits unrestricted use, distribution, and reproduction in any medium, provided the original work is properly cited.

\begin{abstract}
Landslides are one of the dangerous natural phenomena that hinder the development in Penang Island, Malaysia. Therefore, finding the reliable method to predict the occurrence of landslides is still the research of interest. In this paper, two models of artificial neural network, namely, Multilayer Perceptron (MLP) and Cascade Forward Neural Network (CFNN), are introduced to predict the landslide hazard map of Penang Island. These two models were tested and compared using eleven machine learning algorithms, that is, Levenberg Marquardt, Broyden Fletcher Goldfarb, Resilient Back Propagation, Scaled Conjugate Gradient, Conjugate Gradient with Beale, Conjugate Gradient with Fletcher Reeves updates, Conjugate Gradient with Polakribiere updates, One Step Secant, Gradient Descent, Gradient Descent with Momentum and Adaptive Learning Rate, and Gradient Descent with Momentum algorithm. Often, the performance of the landslide prediction depends on the input factors beside the prediction method. In this research work, 14 input factors were used. The prediction accuracies of networks were verified using the Area under the Curve method for the Receiver Operating Characteristics. The results indicated that the best prediction accuracy of $82.89 \%$ was achieved using the CFNN network with the Levenberg Marquardt learning algorithm for the training data set and $81.62 \%$ for the testing data set.
\end{abstract}

\section{Introduction}

Landslide hazard is a particular case of natural hazard which is defined as the probability of occurrence within a specified period of time and within a given area of a potentially damaging phenomenon $[1,2]$. Numerous occurrences of landslides have caused lives to perish and incurred losses in terms of financial stakes, across the entire world annually. However, the main causes behind the occurrence of the landslides are still unspecified. Different factors such as geological, topographic, physical, and human causes (disregard for sustainable form of developments) contribute to landslide occurrences [3]. Therefore, many studies have been conducted and different techniques have been applied to predict the occurrence of landslides. These techniques involve variations and mixtures in approaches, from logical, experience-based analyses, extending to complex mathematical and computer based system.

Over the last two decades, a keen interest has been shown in the application of artificial neural networks (ANNs). It has been widely applied in forecasting, decision making, food industry, agriculture sector, and many other different applications [4-7]. The popularity of ANNs is due in part to their computational simplicity, finite parameterization, and stability. Different ANNs architecture such as the MLP, radial basis function (RBF), and recurrent neural networks (RNN) have been proposed in the literature [8]. Amongst all these models, the most commonly and widely used model for landslide is the MLP model $[9,10]$.

ANNs are one of the techniques which produce good accuracy when used to predict the occurrences of landslides [11]. However, an ideal method for predicting landslide 
occurrence has not been agreed upon yet [12]. Therefore, an intelligent computer system is proposed to enable automatic prediction of landslide using MLP and CFNN in ANNs.

Penang Island is being subject of interest for many studies. Pradhan (2010) produced a landslide hazard map for Penang Island using MLP neural network. Five training sites from Penang island and nine different factors involved in their analysis include slope angle, slope aspect, curvature, distance from drainage, distance from lineament, geology, land cover, soil, and rain precipitation [13].

Pradhan et al. (2010) also investigated the possible application of an artificial neural network model and its crossapplication of weights at three study areas in Malaysia, namely, Penang Island, Cameron Highlands, and Selangor. The weight of each factor was calculated. The factors are, namely, slope angle, slope aspect, plan curvature, altitude, stream power index, wetness index, distance from drainage, distance from road, distance from faults, geology, land use, soil texture, soil material, vegetation index, and topography. The results show that case of the weight using the same test area showed slightly higher accuracy than the weight used for the cross-applied area [10].

Lim et al. (2011) used probabilistic methods such as frequency ratio, statistical index, certainty factor and landslide susceptibility analysis, and logistic regression to produce landslide hazard maps for Penang Island. In their study, twelve factors including four topographic factors were used. The importance of the input factors was not estimated in their study [14].

Oh and Pradhan (2011) applied adaptive neurofuzzy inference system (ANFIS) with seven factors: altitude, slope angle, plan curvature, distance from drainage, distance from road, soil texture, and stream power index on an area of Penang Island covering only $8.064 \mathrm{~km}^{2}$ of Penang Island [15].

Pang et al. (2012) used Decision Tree (DT) to produce landslide hazard mapping for Penang Island with the same twelve factors, used by [14]. DT model was calculated and constructed using the DT algorithm. The use of DT method improves the landslide hazard map where the percentage of past landslide event increases at three risk levels, that is, most hazardous, hazardous, and moderate, while the percentage is reduced in the nonhazardous level [16].

Digital Elevation Model has been generally used as the basic source for extracting the topographic factors such as slope aspect and curvatures. It also is one of the core database sources for several GIS applications [17]. For this study the DEM with 5 meter/pixel resolution was used to extract the slope angle, slope aspect, profile curvature, plan curvature, and general curvature.

Fourteen factors were used as the input features for the MLP and CFNN. These factors are slope angles, slope aspect, profile curvature, plan curvature, general curvature, distance from the road, distance from the fault lines, elevation, distance from the drainages, soil texture, land cover, vegetation cover, geology, and the rain precipitation as a triggering factor. The MLP and CFNN were trained with eleven learning algorithms to produce the most accurate prediction results. The 11 learning algorithms used were Levenberg Marquardt (LM), Broyden Fletcher Goldfarb (BFG), Resilient
Back Propagation (Rp), Scaled Conjugate Gradient (SCG), Conjugate Gradient with Beale (CGB), Conjugate Gradient with Fletcher Reeves updates (CGF), Conjugate Gradient with Polakribiere updates (CGP), One Step Secant (OSS), Gradient Descent (GD), Gradient descent with momentum and adaptive learning rate (GDX) and Gradient Descent with Momentum (GDM) algorithms.

The organization of this paper is as follows. The CFNN and MLP are explained as landslide prediction methods in Section 2. Section 3 introduces the study area and provides descriptions on the data collection and factor extraction. Results of the prediction performance are presented in Section 4. Conclusion is drawn in Section 5. Figure 1 describes the methodology for this work.

\section{MLP and CFNN}

The popularity of the MLP and CFNN comes from their stability, simplicity of application, and smaller structure size for a particular problem, as compared to the other structures [18]. The network learns the relationship between pairs of factors (inputs) and output (responses) vectors by altering the weight and bias values [19]. Figure 2 shows an example of a standard MLP and CFNN. It consists of three layers in the order of input, hidden, and output layer. Each layer consists of independent processing units called neurons [20].

These neurons receive inputs; each input value is multiplied by the weight (the strength of the input). The input is computed using a mathematical function that determines the activation values of the neuron and is then passed to the next layer. The output from the hidden layer is given by

$$
h_{j}=f\left(\sum_{i=1}^{I} w_{i j} x_{i}+b_{j}\right) ; \quad \text { for } 1 \leq j \leq J,
$$

where $h_{j}$ is the output from hidden layer and $x_{i}$ and $w_{i j}$ denote the inputs and the weight from input $i$ to hidden unit $j$ in the first layer, respectively. $b_{j}$ is the bias for hidden unit $j$ and $f(\cdot)$ is the transfer function. For the hidden layer, the tan sigmoid function was used.

The predicted output of the $k$ th node in the output layer is denoted as $y_{k}$ which can be expressed as in

$$
y_{k}=\sum_{j=1}^{J} w_{j k} h_{j} ; \quad \text { for } 1 \leq k \leq K,
$$

where $w_{j k}$ denotes the weights from the hidden layer to the output layer. $k$ denotes the number of outputs neurons. Combining (1) and (2), the complete representation of the output for the MLP network is obtained as in

$$
\begin{gathered}
y_{k}=\sum_{j=1}^{J} w_{j k} f\left(\sum_{i=1}^{I} w_{i j} x_{i}+b_{j}\right) ; \\
\quad \text { for } 1 \leq j \leq J, \quad 1 \leq k \leq K .
\end{gathered}
$$

CFNN network shares the same structure and the work methodology with MLP network. However, CFNN includes 


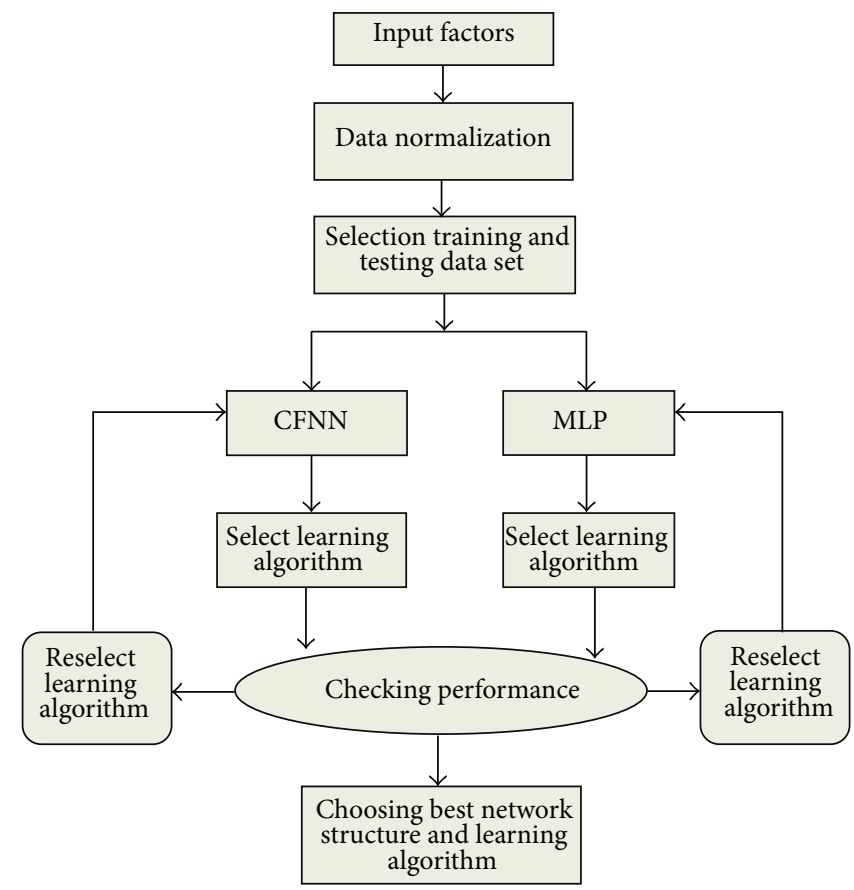

FIGURE 1: Flow chart of the work methodology.

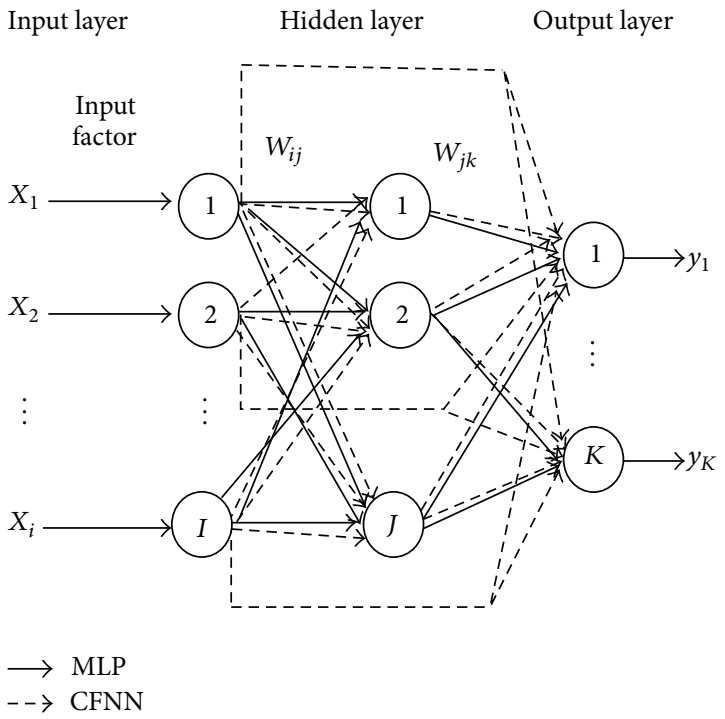

Figure 2: MLP and CFNN.

a weight connection from the input to the output layer and from each layer to the successive layers [21]. As shown in Figure 2, for the CFNN network with $K$ output nodes, $J$ hidden nodes, and $I$ input nodes, the output of the $k$ th neuron, $y_{k}$ in the output layer is given by

$$
y_{k}=\sum_{j=1}^{J} w_{j k} f\left(\sum_{i=1}^{I} w_{i j} x_{i}+b_{j}\right)+\left(\sum_{i=1}^{I} w_{i k} x_{i}+b_{k}\right) ;
$$

for $1 \leq j \leq J, \quad 1 \leq k \leq K$.
Because of the fact that neural networks have numerous numbers of neurons, adjusting of the neural weights without a learning algorithm may be quite difficult. For that, various learning algorithms have been developed and established for two reasons: minimizing the error rate between the actual output and the output results and building up the weights, $w_{i j}$ and $w_{j k}$, for the inputs factors $[22,23]$. In this paper, MLP and CFNN were trained with eleven learning algorithms. Detailed descriptions on the learning algorithms can be found in [24]. Both MLP and CFNN with different learning algorithms are assessed based on their performance in producing landslide hazard map of Penang Island.

\section{Data Collection and Preparation for the Neural Network}

For this work, 14 factors were investigated and analyzed. The data for 14 factors were collected and extracted for the study area. This study is focused on Penang Island which is shown in Figure 3. Study area lies between $5^{\circ} 15^{\prime}$ and $5^{\circ} 30^{\prime} \mathrm{N}$ latitude and $100^{\circ} 10^{\prime}$ and $100^{\circ} 20^{\prime} \mathrm{E}$ longitude. It occupies an area of $285 \mathrm{~km}^{2}$ and is one of the thirteen states of Malaysia. The island is bounded to the north and east by the state of Kedah, to the south by the state of Perak, and to the west by the Straits of Malacca and Sumatra (Indonesia). It consists of both the island of Penang and a coastal strip on the mainland which is known as Province Wellesley. The island of Penang is the study area in this research work. Penang Island experiences frequent landslides, which occur quite frequently during the rainy seasons $[14,15,25]$. Penang Island has a tropical climate with high temperatures of $29^{\circ} \mathrm{C}$ to $32^{\circ} \mathrm{C}$ and humidity ranging from $65 \%$ to $96 \%$. Topographic elevations 


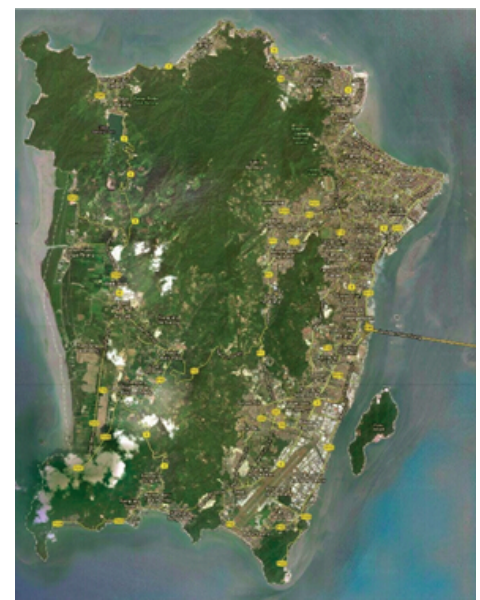

FIgURE 3: Penang Island (source: Google maps).

vary between $0 \mathrm{~m}$ and $820 \mathrm{~m}$ above sea level, and the slope angle ranges from $0^{\circ}$ to $87^{\circ}$. Flat lands make up $43.28 \%$ of the island. Geological data from the Department of Mineral and Geosciences show that Feringgi granite, Batu Maung granite, clay, and sand granite represent more than $72 \%$ of the study area's geology. Vegetation cover consists mainly of forests and fruit plantations.

Data collection on the geographical database of Penang Island was obtained through various government agencies. Factors such as geology, road, fault lines, elevation, drainage, soil texture, land cover, vegetation cover, and rain precipitation maps were obtained from Department of Survey and Mapping Malaysia (JUPEM), Department of Agriculture Malaysia (DOA), Department of Minerals and geosciences Malaysia (JMG), Geographic information System Center of Penang (Pusat PeGIS), Malaysian Meteorological Department (MMD), and Department of Irrigation and Drainage Malaysia (JPS). Topographic factors which include slope angle, slope aspect, profile curvature, plan curvature, and general curvature were extracted from the elevation data [16]. Landslide occurrence locations were also collected and determined. The range of each factor and the ratio of occurrence on the study area are shown in Table 1.

The data is prepared for the neural network, including training data set and testing data set. The data were normalized to range between 0 and 1 , for each of the factors individually based on

Normalised sample $(i)$

$$
=\frac{\text { sample }(i)-\text { minimum sample }(I)}{\text { maximum sample }(I)-\text { minimum sample }(I)},
$$

where the sample $(i)$ is the sample to be normalized and $(I)$ is the minimum or the maximum sample value for every single input factor. The neural network outputs are represented by an output of 1 for landslide and 0 for no landslide. An effective neural network requires a comprehensive trained data set. Therefore 137572 data samples were selected from each factor in this analysis, where 68786 samples represent landslides and 68786 samples represent no landslides. Two-thirds of the data
(91715) were used for training and the remaining one-third (45857) was used for testing. The two neural networks, MLP and CFNN, were trained using the Matlab software.

To determine the network parameters, the experiments were carried out by varying the number of hidden neurons from 1 to 100 . For each number of hidden neuron, the network was trained by varying the number of epochs from 1 to 1000 . The purpose was to find the number of epoch that produced the best generalization for each number of hidden neuron. The optimum epoch and hidden neuron, which produced the minimum value of mean squared error for the testing set, was noted and its prediction accuracy was determined.

\section{Results and Discussions}

Two characteristics were used for the neural network performance analysis, which are the accuracy and the MSE. Model validation using MSE is tested by calculating the mean squared errors after each epoch. The MSE is defined as the average squared error between the actual output and the predicted output. The MSE at every epoch is given by

$$
\mathrm{MSE}=\frac{1}{N} \sum_{i=1}^{N}(y(i)-\widehat{y}(i))^{2},
$$

where $y(i)$ and $\widehat{y}(i)$ are the actual output and the predicted output for a given set of estimated parameters after $t$ epochs, respectively, and $N$ is the number of data that were used to calculate the MSE.

To verify the accuracy of each model, the Receiver Operating Characteristics (ROC) method was used and the Area Under the Curve method (AUC) was calculated for all the models. AUC is one of the popular accepted methods for models prediction in natural hazard and the extracted AUC becomes the value of the accuracy.

The ROC plots the false positive rate on the $X$-axis and the false negative rate on the $Y$-axis. The plot shows the tradeoff between the two rates, where AUC is one of the indicators computed based on ROC. In addition to that, the AUC explains the accuracy of the model in predicting landslides. In general, the lowest value of AUC is 0.5 , which means that the model does not predict any better than a random approach.

Table 2 shows the testing performance for the training data sets that were achieved from the standard MLP and CFN, using the eleven different learning algorithms based on the 14 input factors. Based on the results in Table 2, it can be clearly seen that the performance values vary considerably across the model of the neural network and the learning algorithms. The best performance achieved was obtained through the CFNN model with LM learning algorithm. The accuracy is $82.89 \%$ with MSE of 0.0620 . The worst accuracy of $71.15 \%$ and MSE of 0.1839 was obtained through MLP model with GDM learning algorithm.

The best accuracy rate obtained using MLP was achieved by the LM algorithm, that is, accuracy of $81.57 \%$ with MSE of 0.0910 . On the contrary, the worst accuracy was $71.15 \%$ with MSE of 0.1839 achieved by the GDM algorithm. For CFNN, the worst performance was achieved using the GD algorithm with $71.24 \%$ with MSE of 0.1607 . Meanwhile, 
TABLE 1: Landslide causative factor's ranges and ratio.

\begin{tabular}{|c|c|c|c|c|c|}
\hline \multirow{2}{*}{ Factors } & \multirow{2}{*}{ Class } & \multicolumn{2}{|r|}{ Area (pixels) } & \multicolumn{2}{|r|}{ Ratio } \\
\hline & & Total area & Landslide occurrence area & Total area & Landslide occurrence \\
\hline \multirow{8}{*}{ Elevation (meter) } & $0-79$ & 6641099 & 10902 & $55.2 \%$ & $15.85 \%$ \\
\hline & $80-159$ & 1390848 & 13026 & $11.56 \%$ & $18.94 \%$ \\
\hline & $160-239$ & 1186046 & 12181 & $9.86 \%$ & $17.71 \%$ \\
\hline & $240-319$ & 882426 & 9687 & $7.33 \%$ & $14.08 \%$ \\
\hline & $320-399$ & 608281 & 8491 & $5.06 \%$ & $12.34 \%$ \\
\hline & $400-479$ & 449927 & 6900 & $3.74 \%$ & $10.03 \%$ \\
\hline & $480-559$ & 391076 & 4461 & $3.25 \%$ & $6.49 \%$ \\
\hline & $>560$ & 481490 & 3138 & $4 \%$ & $4.56 \%$ \\
\hline \multirow{7}{*}{ Slope angle (degree) } & $0-7$ & 6318295 & 6100 & $52.52 \%$ & $8.87 \%$ \\
\hline & $8-15$ & 1515746 & 12512 & $12.6 \%$ & $18.19 \%$ \\
\hline & $16-23$ & 2003138 & 19769 & $16.65 \%$ & $28.74 \%$ \\
\hline & $24-31$ & 1490172 & 19504 & $12.39 \%$ & $28.35 \%$ \\
\hline & $32-39$ & 554603 & 8537 & $4.61 \%$ & $12.41 \%$ \\
\hline & $40-47$ & 121293 & 1825 & $1.01 \%$ & $2.65 \%$ \\
\hline & $>48$ & 539 & 539 & $0.23 \%$ & $0.78 \%$ \\
\hline \multirow{9}{*}{ Slope aspect (degree) } & North & 811040 & 7819 & $6.74 \%$ & $11.37 \%$ \\
\hline & North-East & 980909 & 11490 & $8.15 \%$ & $16.70 \%$ \\
\hline & East & 996431 & 9081 & $8.28 \%$ & $13.20 \%$ \\
\hline & South-East & 723126 & 7515 & $6.01 \%$ & $10.93 \%$ \\
\hline & South & 796410 & 7164 & $6.62 \%$ & $10.41 \%$ \\
\hline & South-West & 903353 & 9771 & $7.51 \%$ & $14.20 \%$ \\
\hline & West & 958631 & 8657 & $7.97 \%$ & $12.59 \%$ \\
\hline & North-west & 654463 & 5217 & $5.44 \%$ & $7.58 \%$ \\
\hline & Flat & 52066830 & 2072 & $43.28 \%$ & $3.01 \%$ \\
\hline \multirow{3}{*}{ General curvature } & Convex & 2992360 & 35717 & $24.86 \%$ & $51.92 \%$ \\
\hline & Concave & 3148149 & 26894 & $26.17 \%$ & $39.10 \%$ \\
\hline & Flat & 5890684 & 6175 & $48.97 \%$ & $8.98 \%$ \\
\hline \multirow{3}{*}{ Profile curvature } & Convex & 3098090 & 26030 & $25.75 \%$ & $37.84 \%$ \\
\hline & Concave & 2886983 & 36014 & $23.99 \%$ & $52.35 \%$ \\
\hline & Flat & 6046120 & 6742 & 50.99 & $9.80 \%$ \\
\hline \multirow{3}{*}{ Plan curvature } & Convex & 361329 & 31779 & $30.18 \%$ & $46.19 \%$ \\
\hline & Concave & 2594977 & 31281 & $21.56 \%$ & $45.47 \%$ \\
\hline & Flat & 5804887 & 5726 & $48.26 \%$ & $8.30 \%$ \\
\hline \multirow{17}{*}{ Land cover } & Forest, bush, swam & 6112837 & 52195 & $50.81 \%$ & $75.88 \%$ \\
\hline & Vegetation & 1617410 & 10951 & $13.44 \%$ & $15.92 \%$ \\
\hline & Transport & 894789 & 2288 & $7.44 \%$ & $3.33 \%$ \\
\hline & Settlement & 1476907 & 404 & $12.28 \%$ & $0.59 \%$ \\
\hline & Cemetery & 138389 & 1442 & $1.15 \%$ & $2.1 \%$ \\
\hline & Mining & 31931 & 0 & $0.27 \%$ & $0.0 \%$ \\
\hline & Industry & 192485 & 13 & $1.6 \%$ & $0.019 \%$ \\
\hline & $\begin{array}{l}\text { Government } \\
\text { institution }\end{array}$ & 156625 & 177 & $1.3 \%$ & $0.26 \%$ \\
\hline & Public facility & 217492 & 155 & $1.18 \%$ & $0.23 \%$ \\
\hline & Plains, hills & 303211 & 501 & $2.51 \%$ & $0.73 \%$ \\
\hline & Buildings & 24327 & 0 & $0.2 \%$ & $0 \%$ \\
\hline & Religious area & 41945 & 159 & $0.35 \%$ & $0.23 \%$ \\
\hline & Business & 205595 & 0 & $1.71 \%$ & $0 \%$ \\
\hline & Sea, lake, river & 267665 & 430 & $2.22 \%$ & $0.63 \%$ \\
\hline & Public utility & 56358 & 71 & $0.47 \%$ & $0.1 \%$ \\
\hline & Livestock & 81141 & 0 & $0.67 \%$ & $0 \%$ \\
\hline & Education & 212085 & 0 & $1.76 \%$ & $0 \%$ \\
\hline
\end{tabular}


TABle 1: Continued.

\begin{tabular}{|c|c|c|c|c|c|}
\hline \multirow{2}{*}{ Factors } & \multirow{2}{*}{ Class } & \multicolumn{2}{|r|}{ Area (pixels) } & \multicolumn{2}{|r|}{ Ratio } \\
\hline & & Total area & Landslide occurrence area & Total area & Landslide occurrence \\
\hline \multirow{14}{*}{ Vegetation cover } & Forest, plant, Bush & 5441433 & 51148 & $45.23 \%$ & $74.36 \%$ \\
\hline & Swamp & 412778 & 960 & $3.43 \%$ & $1.4 \%$ \\
\hline & Mixed farms & 258984 & 80 & $2.15 \%$ & $0.12 \%$ \\
\hline & Fruit farm & 145514 & 1683 & $1.21 \%$ & $2.45 \%$ \\
\hline & Oil farm & 968301 & 9023 & $8.05 \%$ & $13.12 \%$ \\
\hline & Sugarcane & 176678 & 0 & $1.47 \%$ & $0 \%$ \\
\hline & Vegetable & 156 & 0 & $0.0013 \%$ & $0 \%$ \\
\hline & Farm & 55599 & 87 & $0.46 \%$ & $0.13 \%$ \\
\hline & Coconut & 79156 & 0 & $0.66 \%$ & $0.0 \%$ \\
\hline & Pineapple & 81 & 0 & $0.00067 \%$ & $0.0 \%$ \\
\hline & Paddy & 126263 & 0 & $1.05 \%$ & $0.0 \%$ \\
\hline & Rubber & 2241 & 0 & $0.019 \%$ & $0.0 \%$ \\
\hline & Others & 65338 & 208 & $0.54 \%$ & $0.3 \%$ \\
\hline & None & 4298671 & 5597 & $35.73 \%$ & $8.14 \%$ \\
\hline \multirow{11}{*}{ Distance from fault line } & $0-100$ & 641379 & 7164 & $5.33 \%$ & $10.41 \%$ \\
\hline & $101-200$ & 651750 & 3427 & $5.42 \%$ & $4.98 \%$ \\
\hline & $201-300$ & 643860 & 1939 & $5.35 \%$ & $2.82 \%$ \\
\hline & $301-400$ & 637145 & 4272 & $5.30 \%$ & $6.21 \%$ \\
\hline & $401-500$ & 630562 & 5715 & $5.24 \%$ & $8.31 \%$ \\
\hline & $501-600$ & 611528 & 4756 & $5.08 \%$ & $6.92 \%$ \\
\hline & $601-700$ & 588891 & 5671 & $4.89 \%$ & $8.24 \%$ \\
\hline & $701-800$ & 549700 & 4855 & $4.57 \%$ & $7.06 \%$ \\
\hline & $801-900$ & 511179 & 6090 & $4.25 \%$ & $8.85 \%$ \\
\hline & $9001-1000$ & 457995 & 3593 & $3.81 \%$ & $5.22 \%$ \\
\hline & $>1000$ & 6107204 & 21298 & $50.76 \%$ & $30.96 \%$ \\
\hline \multirow{10}{*}{ Distance from road } & $0-49$ & 3807202 & 5863 & $31.64 \%$ & $8.52 \%$ \\
\hline & $50-99$ & 1044665 & 2056 & $8.68 \%$ & $2.99 \%$ \\
\hline & $100-149$ & 748374 & 3324 & $6.22 \%$ & $4.83 \%$ \\
\hline & $150-199$ & 598005 & 3053 & $4.97 \%$ & $4.44 \%$ \\
\hline & $200-249$ & 504546 & 3267 & $4.19 \%$ & $4.75 \%$ \\
\hline & $250-299$ & 440547 & 3368 & $3.66 \%$ & $4.9 \%$ \\
\hline & $300-349$ & 389709 & 3787 & $3.24 \%$ & $5.51 \%$ \\
\hline & $350-399$ & 354222 & 4152 & $2.94 \%$ & $6.04 \%$ \\
\hline & $400-449$ & 328068 & 2805 & $2.73 \%$ & $4.08 \%$ \\
\hline & $>450$ & 3815855 & 37111 & $31.72 \%$ & $53.95 \%$ \\
\hline \multirow{10}{*}{ Distance from drainage } & $0-49$ & 4229076 & 41931 & $35.15 \%$ & $60.96 \%$ \\
\hline & $50-99$ & 2214851 & 11711 & $18.41 \%$ & $17.03 \%$ \\
\hline & $100-149$ & 1497866 & 6864 & $12.45 \%$ & $9.98 \%$ \\
\hline & $150-199$ & 980562 & 3980 & $8.15 \%$ & $5.79 \%$ \\
\hline & $200-249$ & 643367 & 1943 & $5.35 \%$ & $2.82 \%$ \\
\hline & $250-299$ & 455199 & 1003 & $3.78 \%$ & $1.46 \%$ \\
\hline & $300-349$ & 344950 & 586 & $2.87 \%$ & $0.85 \%$ \\
\hline & $350-399$ & 274824 & 517 & $2.28 \%$ & $0.75 \%$ \\
\hline & $400-449$ & 224731 & 205 & $1.87 \%$ & $0.30 \%$ \\
\hline & $>450$ & 1165767 & 46 & $9.69 \%$ & $0.07 \%$ \\
\hline \multirow{6}{*}{ Geology } & $\begin{array}{l}\text { Muka head } \\
\text { microgranite }\end{array}$ & 174024 & 1431 & $1.45 \%$ & $2.08 \%$ \\
\hline & Feringgi, granite & 2343321 & 22931 & $19.48 \%$ & $33.34 \%$ \\
\hline & $\begin{array}{l}\text { Tanjung } \\
\text { Bunga granite }\end{array}$ & 2751458 & 19292 & $22.87 \%$ & $28.05 \%$ \\
\hline & $\begin{array}{l}\text { Sungai area } \\
\text { granite }\end{array}$ & 318909 & 500 & $2.65 \%$ & $0.73 \%$ \\
\hline & $\begin{array}{l}\text { Batu Maung } \\
\text { granite }\end{array}$ & 3359896 & 24365 & $27.93 \%$ & $35.42 \%$ \\
\hline & Clay, sand, granite & 3083585 & 267 & 25.63 & $0.39 \%$ \\
\hline
\end{tabular}


TABle 1: Continued.

\begin{tabular}{|c|c|c|c|c|c|}
\hline \multirow{2}{*}{ Factors } & \multirow{2}{*}{ Class } & \multicolumn{2}{|r|}{ Area (pixels) } & \multicolumn{2}{|r|}{ Ratio } \\
\hline & & Total area & Landslide occurrence area & Total area & Landslide occurrence \\
\hline \multirow{6}{*}{ Soil texture } & Sand & 133506 & 0 & $1.11 \%$ & $0.00 \%$ \\
\hline & Sandy clay & 443859 & 505 & $3.69 \%$ & $0.74 \%$ \\
\hline & Loam & 6535957 & 67126 & $54.33 \%$ & $97.59 \%$ \\
\hline & Sandy loam & 1606303 & 790 & 13.35 & $1.15 \%$ \\
\hline & Silty clay & 332707 & 55 & $2.77 \%$ & $0.08 \%$ \\
\hline & Urban land & 2978861 & 309 & $24.76 \%$ & $0.45 \%$ \\
\hline \multirow{9}{*}{ Rain precipitation } & $2254-2319.8$ & 85398 & 849 & $0.71 \%$ & $1.23 \%$ \\
\hline & $2319.9-2379.3$ & 549900 & 1571 & $4.57 \%$ & $2.28 \%$ \\
\hline & $2379.4-2433.2$ & 1489192 & 10850 & $12.38 \%$ & $15.77 \%$ \\
\hline & $2433.3-2481.9$ & 2815573 & 16632 & $23.4 \%$ & $24.18 \%$ \\
\hline & $2481.0-2535.8$ & 3202204 & 6815 & $26.62 \%$ & $9.91 \%$ \\
\hline & $2535.9-2595.8$ & 3003842 & 22832 & $24.97 \%$ & $33.19 \%$ \\
\hline & $2595.9-2661.1$ & 559762 & 6617 & $4.65 \%$ & $9.61 \%$ \\
\hline & $2661.2-2722.8$ & 227570 & 1755 & $1.89 \%$ & $2.55 \%$ \\
\hline & $2733.9-2903$ & 97752 & 865 & $0.81 \%$ & $1.26 \%$ \\
\hline
\end{tabular}

TABLE 2: The training accuracy (\%) and MSE for MLP and CFNN using the eleven learning algorithms with data set.

\begin{tabular}{lcccccccc}
\hline Network type & \multicolumn{3}{c}{ MLP } & & \multicolumn{3}{c}{ CFNN } \\
Learning algorithm & Accuracy & MSE & Hidden nodes & Epoch & Accuracy & MSE & Hidden nodes & Epoch \\
\hline LM & 81.57 & 0.0910 & 82 & 22 & 82.89 & 0.0620 & 72 & 33 \\
BFG & 81.35 & 0.1150 & 60 & 191 & 79.68 & 0.1326 & 68 \\
Rpro & 77.62 & 0.1535 & 52 & 274 & 77.73 & 0.1290 & 89 & 152 \\
SCG & 77.22 & 0.1548 & 81 & 178 & 77.19 & 0.1280 & 142 \\
CGB & 77.28 & 0.1534 & 80 & 147 & 78.14 & 0.1258 & 72 & 64 \\
CGF & 75.75 & 0.1625 & 31 & 134 & 76.76 & 0.1334 & 23 \\
CGP & 76.54 & 0.1578 & 55 & 144 & 76.28 & 0.1370 & 82 \\
OSS & 76.13 & 0.1624 & 49 & 168 & 74.98 & 0.1422 & 18 \\
GD & 71.23 & 0.1836 & 80 & 989 & 71.24 & 0.1607 & 82 \\
GDX & 72.34 & 0.1791 & 19 & 140 & 72.27 & 0.1590 & 148 \\
GDM & 71.15 & 0.1839 & 87 & 999 & 71.24 & 0.1606 & 25 \\
\hline
\end{tabular}

the LM algorithm showed the best accuracy regardless of the neural network model. The LM learning algorithm achieved the best accuracy of $82.89 \%$, with MSE of 0.0620 and $81.57 \%$ with MSE of 0.0910 for CFNN and MLP, respectively. On the other hand, GDM algorithm has the worst results in MLP neural network, whereas GD algorithm has the worst results in CFNN.

Overall, CFNN model achieved better accuracy and MSE as compared to MLP model, using six learning algorithms, that is, LM, Rprop, CGB, CGF, GD, and GDM, while for learning algorithms including BFG, SCG, OSS, CGP, and GDX, the MLP achieved better accuracy compared to CFNN.

In Table 3, the testing data sample was tested by using the same networks parameters. As expected the test accuracy result followed the training accuracy result where the CFNN with LM training algorithm achieved the best accuracy. Figures 4, 5, 6, and 7 show the ROC of CFNN and MLP with 11 learning algorithms applied on the testing data set.
TABLE 3: Accuracy obtained using testing data set.

\begin{tabular}{lcc}
\hline Network type & $\begin{array}{c}\text { MLP } \\
\text { Learning algorithm }\end{array}$ & $\begin{array}{c}\text { CFNN } \\
\text { Testing data accuracy }\end{array}$ \\
\hline LM & 81.11 & 81.62 \\
BFG & 79.69 & 75.80 \\
Rprop & 75.61 & 77.93 \\
SCG & 75.58 & 76.34 \\
CGB & 75.52 & 75.81 \\
CGF & 74.47 & 75.16 \\
CGP & 74.96 & 74.82 \\
OSS & 74.37 & 73.87 \\
GD & 71.04 & 71.17 \\
GDX & 71.87 & 71.84 \\
GDM & 70.90 & 70.91 \\
\hline
\end{tabular}




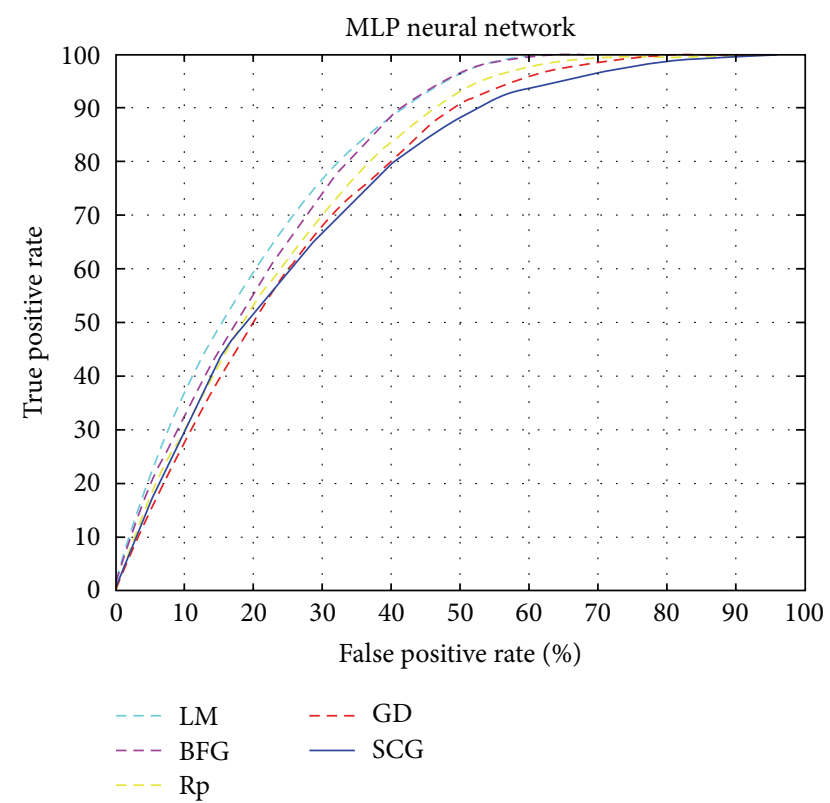

FIGURE 4: ROC curve for MLP neural network trained with LM, BFG, Rp, GD, and SCG.

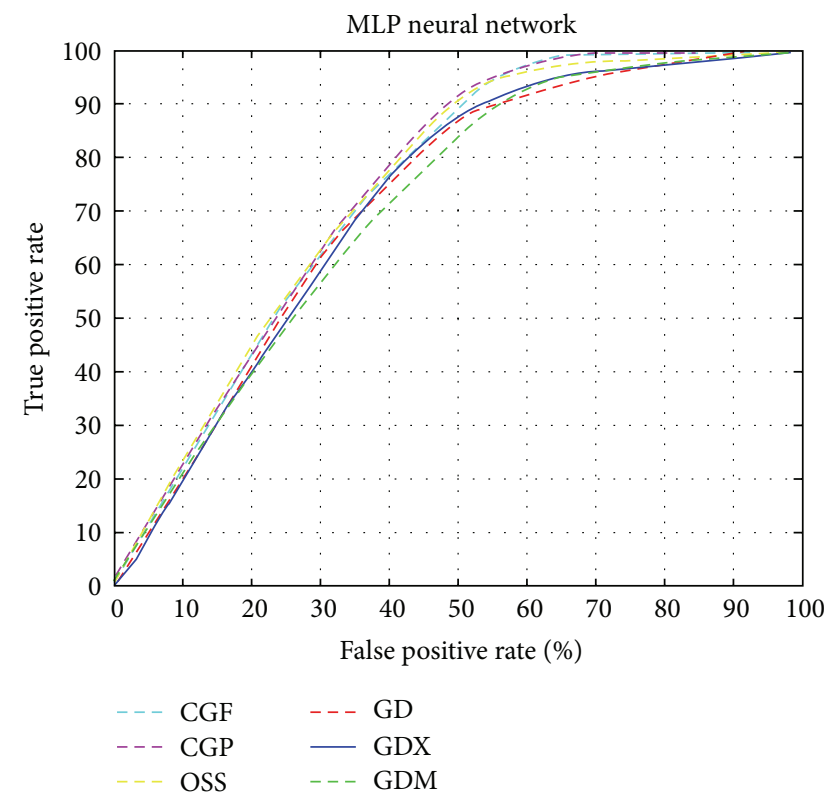

FIGURE 5: ROC curve for MLP neural network trained with CGF, CGP, OSS, GD, GDX, and SCG.

\section{Conclusion}

In this paper, fourteen suitable factors were collected and applied as input factors for ANN models. Two efficient neural network models, MLP and CFNN, are proposed and compared using eleven learning algorithms. The 14 factors show a good performance in predicting the landslide occurrence of Penang Island with accuracy up to $81.62 \%$. The comparison results show that the CFNN network trained with LM can successfully be adopted for prediction of the landslide

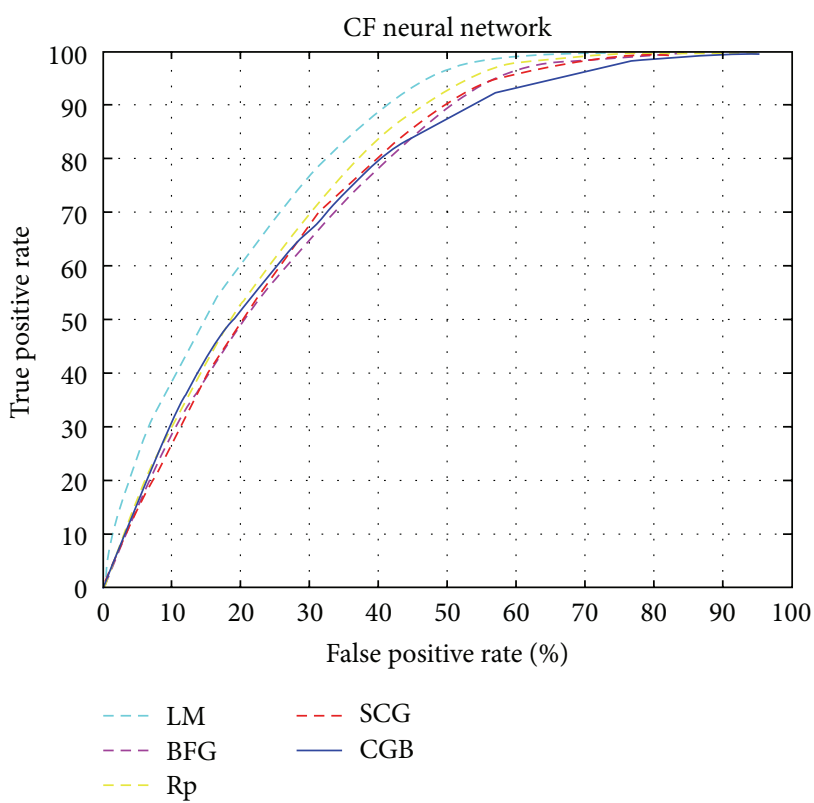

FIGURE 6: ROC curve for CF neural network trained with LM, BFG, Rp, SCG, and CGB.

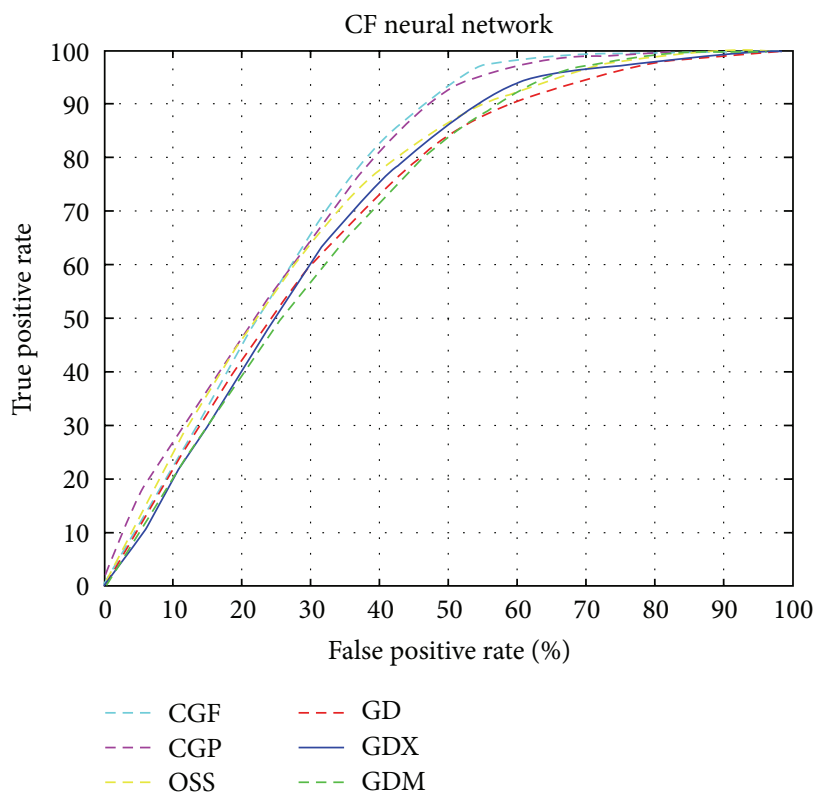

FIGURE 7: ROC curve for CF neural network trained with CGF, CGP, OSS, GD, GDX, and SCG.

with significantly high performance. Moreover, applying the CFNN for prediction of the landslide on different study areas could be subject of interest in the future work.

\section{Conflict of Interests}

The authors declare that there is no conflict of interests regarding the publication of this paper. 


\section{Acknowledgments}

This research was supported by Ministry of Education, Malaysia (Grant no. 203/PJJAUH/6711279), Japan Science and Technology Agency (JST)/Japan International Cooperation Agency (JICA), and Science and Technology Research Partnership for Sustainable Development (SATREPS). The authors would also like to thank the JKR, JPS, JMG, and PEGIS, Malaysia, for the data used in this research.

\section{References}

[1] D. J. Varnes, Landslide Hazard Zonation: Preview of Principals and Practice, vol. 3 of Natural Hazards, UNESCO, International Assciation of Engineering Geologists, Commission on Landslides and Other Mass Movementson Slopes, Paris, France, 1984.

[2] D. J. Varnes, Landslide Hazard Zonation: Preview of Principals and Practice. Paris, UNESCO, Int Assciation of Engineering Geologists, Commission on Landslides and Other Mass Movementson Slopes, Natural Hazards V-3 Pp176, 1984.

[3] J. N. Hutchinson, "Keynote paper: landslide hazard assessment," in Landslides, Proc. Sixth Int. Symp. on Landslides, February, Christchurch, New Zealand, D. H. Bell, Ed., vol. 3, pp. 1805-1841, A.A. Balkema, Rotterdam, The Netherlands, 1995.

[4] G. Zhang, B. E. Patuwo, and M. Y. Hu, "Forecasting with artificial neural networks: the state of the art," International Journal of Forecasting, vol. 14, no. 1, pp. 35-62, 1998.

[5] L. Sanzogni and D. Kerr, "Milk production estimates using feed forward artificial neural networks," Computers and Electronics in Agriculture, vol. 32, no. 1, pp. 21-30, 2001.

[6] M. Kumar, N. S. Raghuwanshi, R. Singh, W. W. Wallender, and W. O. Pruitt, "Estimating evapotranspiration using artificial neural network," Journal of Irrigation and Drainage Engineering, vol. 128, no. 4, pp. 224-233, 2002.

[7] M. Lashkarbolooki, Z. S. Shafipour, and A. Z. Hezave, "Trainable cascade-forward back-propagation network modeling of spearmint oil extraction in a packed bed using $\mathrm{SC}-\mathrm{CO}_{2}$," The Journal of Supercritical Fluids, vol. 73, pp. 108-115, 2013.

[8] M. S. Alkhasawneh, U. K. Bt Ngah, T. L. Tien, and N. A. B. Mat Isa, "Landslide susceptibility hazard mapping techniques review," Journal of Applied Sciences, vol. 12, no. 9, pp. 802-808, 2012.

[9] S. Lee, J. Ryu, K. Min, and J. Won, "Development of two artificial neural network methods for landslide susceptibility analysis," in Proceedings of the IEEE International Geoscience and Remote Sensing Symposium (IGARSS '01), vol. 5, pp. 2364-2366, 2001.

[10] B. Pradhan, L. Saro, and M. F. Buchroithner, "A GIS-based backpropagation neural network model and its cross-application and validation for landslide susceptibility analyses," Computers, Environment and Urban Systems, vol. 34, no. 3, pp. 216-235, 2010.

[11] S. Lee, J. Choi, and K. Min, "Probabilistic landslide hazard mapping using GIS and remote sensing data at Boun, Korea," International Journal of Remote Sensing, vol. 25, no. 11, pp. 20372052, 2004.

[12] F. Guzzetti, A. Carrara, M. Cardinali, and P. Reichenbach, "Landslide hazard evaluation: a review of current techniques and their application in a multi-scale study, Central Italy," Geomorphology, vol. 31, no. 1-4, pp. 181-216, 1999.
[13] B. Pradhan and S. Lee, "Delineation of landslide hazard areas on Penang Island, Malaysia, by using frequency ratio, logistic regression, and artificial neural network models," Environmental Earth Sciences, vol. 60, no. 5, pp. 1037-1054, 2010.

[14] K.-W. Lim, L. T. Tay, and H. Lateh, "Landslide hazard mapping of Penang island using probabilistic methods and logistic regression," in Proceedings of the IEEE International Conference on Imaging Systems and Techniques (IST '11), pp. 273-278, May 2011.

[15] H.-J. Oh and B. Pradhan, "Application of a neuro-fuzzy model to landslide-susceptibility mapping for shallow landslides in a tropical hilly area," Computers \& Geosciences, vol. 37, no. 9, pp. 1264-1276, 2011.

[16] P. K. Pang, L. T. Tay, and H. Lateh, "Landslide hazard mapping of Penang Island using decision tree model," in Proceedings of the International Conference on Systems and Electronic Engineering (ICSEE '12), December 2012.

[17] Q. Zhou and X. Liu, "Analysis of errors of derived slope and aspect related to DEM data properties," Computers and Geosciences, vol. 30, no. 4, pp. 369-378, 2004.

[18] M. Barletta and A. Gisario, "An application of neural network solutions to laser assisted paint stripping process of hybrid epoxy-polyester coating on aluminum substrates," Surface and Coatings Technology, vol. 200, no. 24, pp. 6678-6689, 2006.

[19] M. S. Al-Batah, N. A. Mat Isa, K. Z. Zamli, Z. M. Sani, and K. A. Azizli, "A novel aggregate classification technique using moment invariants and cascaded multilayered perceptron network," International Journal of Mineral Processing, vol. 92, no. 1-2, pp. 92-102, 2009.

[20] S. Haykin, Neural Networks a Comprehensive Foundation, 2nd edition, 1999.

[21] M. Kurban and U. B. Filik, "A new approach for next day load forecasting integrating artificial neural network model with weighted frequency bin blocks," in Neural Information Processing, M. Ishikawa, K. Doya, H. Miyamoto, and T. Yamakawa, Eds., vol. 4985, pp. 703-712, Springer, Berlin, Germany, 2008.

[22] C. M. Bishop, Neural Networks for Pattern Recognition, Oxford University Press, Oxford, UK, 1995.

[23] G. Hinton, D. E. Rumelhart, and RJ. Williams, "Learning internal representations by error propagation," in Parallel Distributed Processing: Explorations in the Microstructure of Cognition, D. E. Rumelhart and J. L. McClelland, Eds., vol. 1, pp. 318-362, MIT Press, Cambridge, UK, 1986.

[24] K. K. Aggarwal, Y. Singh, P. Chandra, and M. Puri, "Bayesian regularization in a neural network model to estimate lines of code using function points," Journal of Computer Sciences, vol. 1, no. 4, pp. 505-509, 2005.

[25] New Starits Time, Don't Over-Develop Penang to Avoid Landslides, 2012, http://www.nst.com.my/latest/don-t-over-developpenang-to-avoid-landslides-1.193992. 


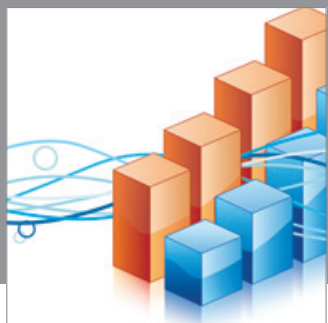

Advances in

Operations Research

mansans

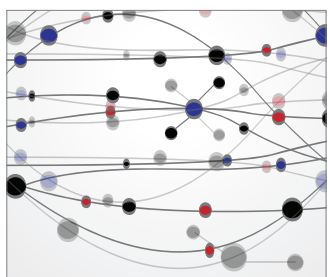

The Scientific World Journal
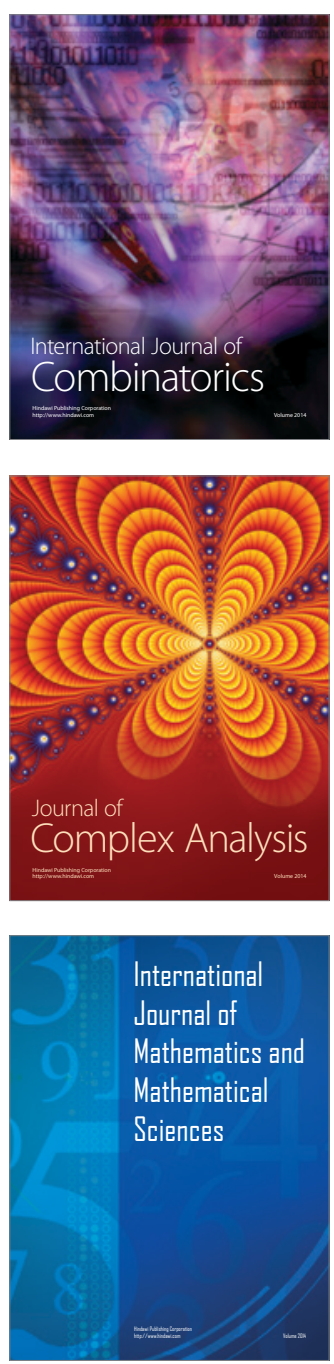
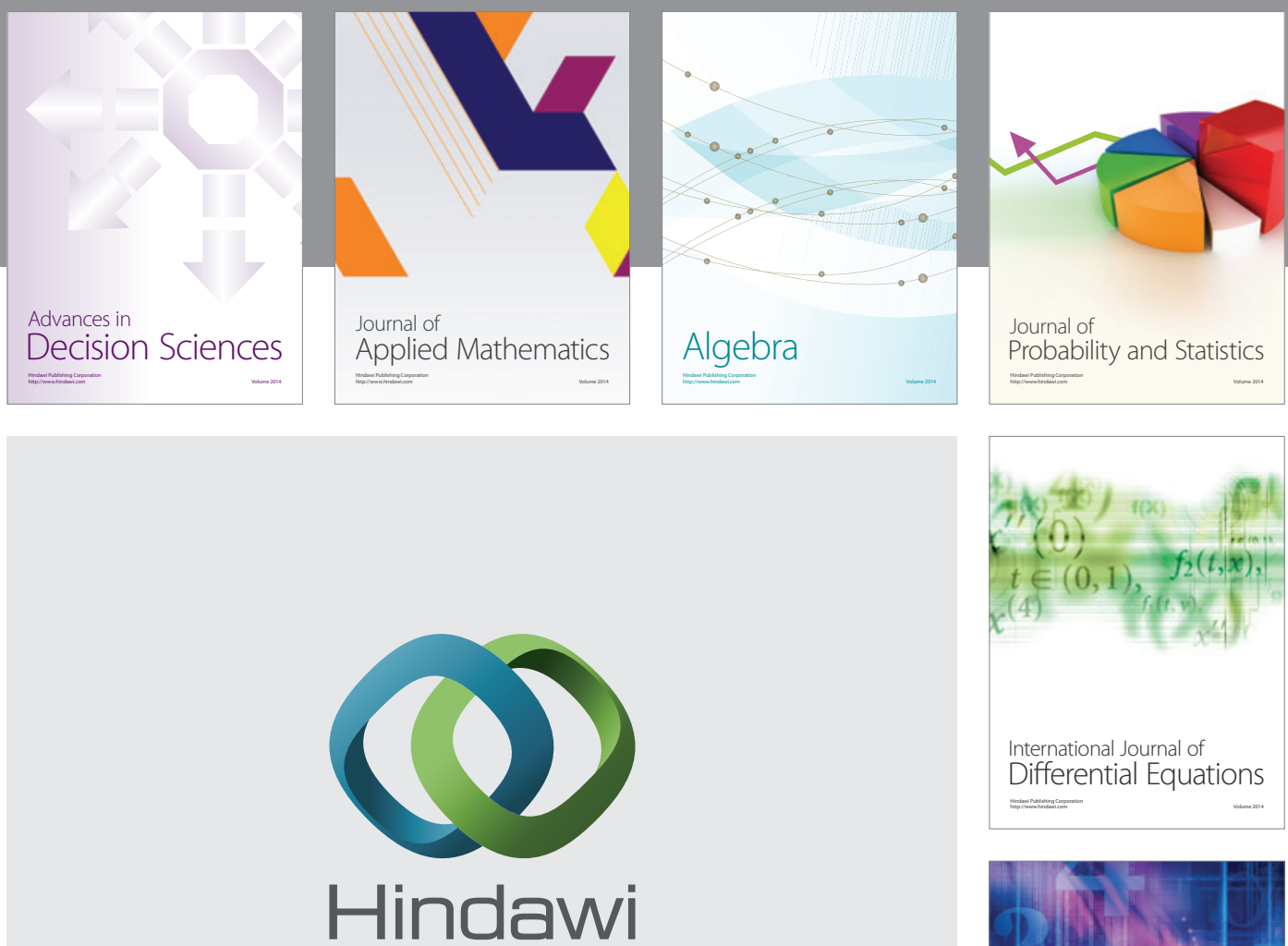

Submit your manuscripts at http://www.hindawi.com
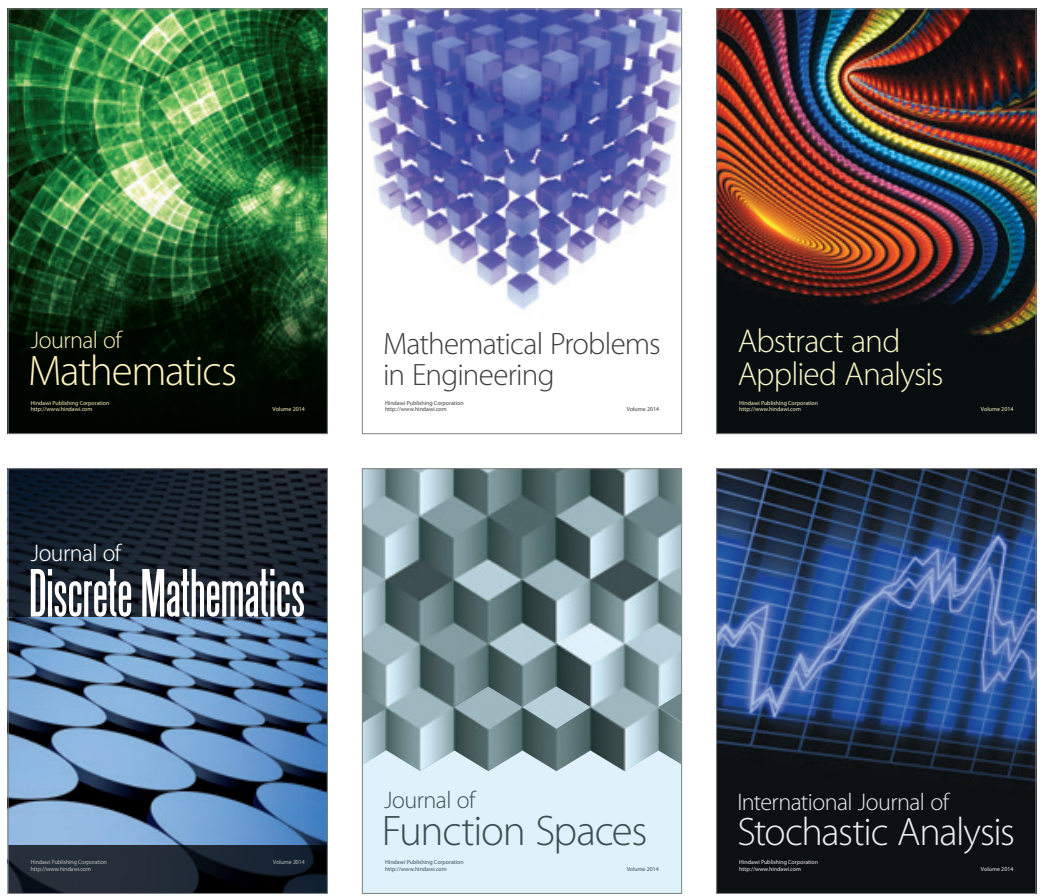

Journal of

Function Spaces

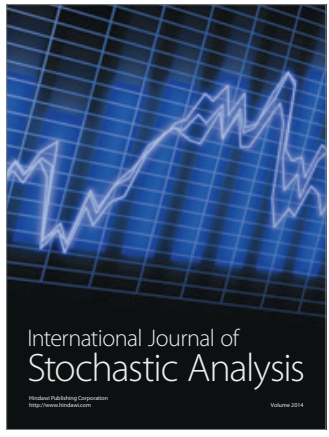

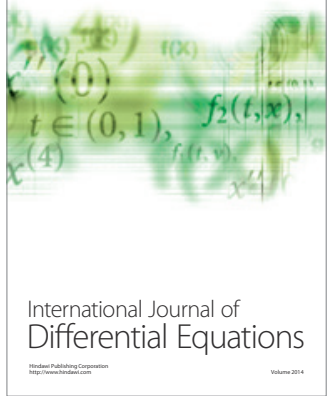
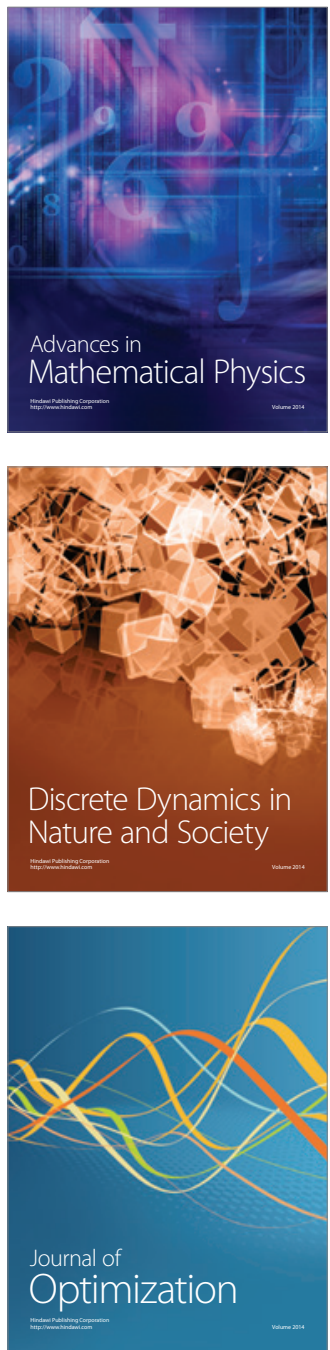